\title{
Interactive lighting art installation in virtual environments as a stimulus for public Ownership in urban development - Brighter Brunnshög
}

\author{
Boa $\mathrm{Kim}^{1 *}$,Emmanouil Xylakis ${ }^{2}$, and Georgios Triantafyllidis ${ }^{2}$ \\ ${ }^{1}$ Dept. of Sculpture, College of Fine Arts, Seoul National University, 1 Gwanak-ro, Gwanak-gu, \\ Seoul 08826, South Korea \\ ${ }^{2}$ Dept. of Architecture, Design \& Media Technology, Aalborg University Copenhagen A.C. Meyers \\ Vænge 15, 2450 Copenhagen SV, Denmark
}

\begin{abstract}
Urban development projects are often ${ }^{1}$ opposed by residents due to a lack of sense of ownership over the project. This study is a methodological approach in creating interactive lighting art installations in virtual environments to stimulate this sense of ownership. The study is part of the Brighter Brunnshög project, which is the initial stage of the urban development plan for new research centres in Brunnshög, Sweden. The main goal of this research is to explore the impact of virtual lighting art installations on residents' attitudes toward the urban development of their area. The research is based on qualitative field studies and focus group interviews, and was assessed with questionnaires. The design itself is based on the results of the research data and consists of three criteria; awareness, mutuality, and adaptability. The results of the assessment indicate that interactive lighting art installations in virtual environments have the potential to create awareness of areas under urban development, which is a fundamental condition for creating place attachment, and by extension, a sense of ownership over the project.
\end{abstract}

\section{Introduction and motivation}

Urban development, which invariably entails construction programs, is often not welcomed by local residents since, for many, it signifies losing a tight-knit location-based community [1]. Despite the possible advantages that come with urban development, losses are weighted more heavily than gains in what is referred to as endowment effect [2]. This aspect and understanding of place and community attachment has become part and parcel of the planning stages of current day urban development projects [3]. As such, planners put in place schemes to encourage continued use of the sites under development where possible, and as such prevent a total detachment and subsequent discontent by the public. To address the fear of loss experienced by the public, it is necessary to support the local sense of heritage, culture, and activities during the construction $[4,5,6]$. These elements of inclusion are subject to requirements relating to time, control and organization. Firstly, for the process to be

*Corresponding author: avo07@snu.ac.kr 
successful, the public need to be included for a certain minimum amount of time in each area of the development [4]. Secondly, the public need to have certain control over what Strahilevitz and Loewenstein (1998) call the entity, i.e., the urban development, by using their own system. Finally, self-investment scores highest when these achievements are based on self-organization [6].

The above-mentioned three conditions have been argued by Van Dyne, Pierce, Vandewalle \& Kostova to relate directly to attachment, and in extension of this, a sense of psychological ownership over the area [7,8]. Since these conditions imply that attachment cannot be moved from one place to another, and since the physical aspects of the space to which they are attached will change significantly, an alternative platform must be found which represents their routines, and which maintains their sense of heritage as the site transforms. This point of attachment and ownership can be addressed by using an interactive lighting installation based on an art-design approach.

With the urban development initiative Brighter Brunnshog from energy firm Kraftringen as an example, I will argue for the use of an interactive lighting installation in a virtual environment representing the area under development, to promote a sense of ownership by local residents over urban development projects, and as such promote a positive attitude towards the development of the area.

\section{An example project - Brighter Brunnshög}

Brunnshög, an area northeast of Lund, Sweden, consists mainly of farmland and has a population of around 14.000. The urban development of the area is projected to increase the population to around 40.000, and include the development of new infrastructure and transportation networks. The urban development is substantial, and Lund's municipality has started the construction of a residential area, a science park, and a research centre housing the world's biggest electron microscope. While construction is well underway for the science village, the residential area and the research centre, two sections remain untouched: a small section of woodland including a conservation protected area, and a section used for local community-based activities, including a small forest with willow huts. The current users of the area are residents and workers in nearby towns such as Norra Faläden, Ideon Science Park and Lund itself.

The Brighter Brunnshög project, run by the Swedish energy firm Kraftringen, forms an important public relations part of the urban development of the area, and as such, is responsible for both informing the residents about the project, and ensuring positive feedback. The proposal to use artistic lighting design as a tool to maintain a smooth transition for the residents and users of the area falls under its auspice.

The study consists of two parts: firstly, the design development of the interactive art installation based on field studies and end-user research, and secondly, the process of creating the virtual environment, the virtual installation with its lighting, and the interactive system that connects the site, the installation and the users. The evaluation within this research is aimed at understanding the psychological impact of the virtual installation on people's attitudes within Kraftringen's Brighter Brunnshög project, and assessing its potential as a tool to reduce the alienation felt by residents in urban development projects. 


\section{Related studies}

\subsection{Art and design: abstraction and factum}

Although the primary parameter of the installation would be to maintain a sense of public ownership over the urban development of the area, the design and content of the installation must be based on anthropological studies and methodologies. However, an installation faces two challenges stemming from the differences between design and art. Any design is fundamentally factual and instrumental in nature, rather than abstracting [9]. On the other hand, the aspect of abstraction is an equally important parameter of the installation; i.e., the installation must present in abstract form the continued connection and heritage of the public after their site has physically changed. Rather than design, abstraction requires art [9]. Art can stimulate personal imagination and appeal to the subconscious. However, it relies heavily on the artist's personal understanding, and as such may lack the insight to understand the public and the space it is situated in. This understanding is critical if one is to create a sense of ownership over an urban development project in which both the public and its space are equally important. Meeting both requirements; i.e., the abstraction and connectivity of heritage, and the interactive functionality of design, implies that an installation that is simultaneously a work of art as well as a design.

\subsection{Light as artistic design}

The use of light within public art and architecture is not unique, especially in its ability to create public realms [10]. In the past, lighting has been an essential, yet ancillary tool to highlight works of art, or make them visible during the night. With the development of media technology however, lighting has taken a more prominent position as a medium in its own right. At the same time, urban lighting design has widened its scope from that of optimizing the existing architectural environment and urban planning, to assigning itself as a platform which allows users to interact with their surroundings. Urban lighting design and public art share a similar functional development: turning a space to a place, and have thus gravitated towards each other and converged $[11,12]$. Designers who were once traditionally viewed as optimizers rather than creators have started to form a more pronounced personal identity by shocking people with bold decisions [13]. Artists, on the other hand, who traditionally sought merely to create a bond between a created object and those who viewed it, have now reached out beyond the viewer and into their physical and metaphysical spaces, adding new value to not just their experience, but equally their surroundings and their lives.

\subsection{The key - ownership}

As touched upon earlier, user-ownership is an important element in urban development, and is therefore a key aspect of the current proposed lighting installation. Pierce, Kostova \& Dirk (2001) have proposed three routes to psychological ownership: intimacy, investment and control. In other words, by intimately knowing, investing in, and controlling the target, the latter of which can be both material and immaterial, one can create psychological ownership.

In addition, in a study on water supply systems, Marks \& Davis, (2012) showed that households which contributed to the water projects, rather than pay for them, tended to have a stronger sense of ownership not only over the project, but equally over the materials they frequently used, e.g. pipes, etc. 


\subsection{The link - ownership in art, design and urban planning}

Art and design each relate to different aspects of cognition. The combination of both means that the functionality of design can convey the abstraction of art in the sense of Cupchik \& László. Yet besides these general qualities, art and design equally have a more intimate connection with the aspect of ownership, and as a platform can affect urban development. Guetzkow (2002) has argued that art impacts not only mechanisms of the psychological individual, but equally wider cultural and socio-economic mechanisms of the community. As such, art is shown to induce positive psychological responses and boost self-esteem, which are key conditions of ownership. Similar to research on psychological ownership, designoriented studies equally show the correlation between design and affective response, as well as design and attachment [6].

Ownership has equally been the subject of studies in urban development. Riger \& Lavrakas emphasized that by providing opportunities for social interaction, neighbourhoods can provide a sense of belonging for people and thus may foster a "psychological sense of community". Furthermore, it has also been argued that public art should be able to generate a sense of ownership by forging the connection between citizens, city spaces and their meaning as places [14].

\subsection{VR as a platform for architectural projects}

VR offers users spatial experiences with time and lighting, and the importance of using VR as a presentation tool in architectural fields is well documented. Further, its cost efficiency compared to real construction and maintenance have equally increased demands for VR in various other fields. This is equally relevant in the field of lighting, which is a multidimensional design element, and which is spatial and temporal in nature. Because lighting requires a deeper spatial understanding, researchers are encouraged to use VR as a design tool [15].

\section{Design research methodology}

The design occurred in two phases: firstly, the area of urban development was analysed to understand the meaning it had for the local inhabitants and users. This was key in identifying the aspects over which ownership would be given during the development of the area. Secondly, the analysis had to be translated into an installation within a lighting art-design framework. This installation would be a platform of interactivity and communication between the local inhabitants and users of the area under development.

Since research on ownership, and its correlation with art and design include disparate research fields, e.g. psychology, urban planning based on site research, and art and design, a tool is needed to weave them together. Because this study deals with social phenomena, an ethnographic approach has been applied to interrelate various factors such as space, actors, feelings, and goals [16]. In this study descriptive observations on the activity area paralleled with focus group interviews for both the quantitative and qualitative data about the users. With respects to the site and the physical environment, the descriptive observation is supported by the TI3 report [17], the formal study for the city plan, and statistical data from Lund Kommune.

The observation and analysis of the individual locations of local activity, i.e., a local farming area and a willow hut area, was conducted based on a descriptive question matrix approach. As such, relevant questions were chosen from the matrix in order to get a better understanding of the meaning and use of the areas [16]. 
In the analysis of the area, a mixed method approach was applied in which qualitative data and quantitative data were integrated. Each data strand was obtained and analysed separately, and used to enrich the understanding of the data in a holistic sense. As such, the convergent parallel model of mixed method was used [18]. Within this the semi-structured focus group, interviews and observations resulted in qualitative data, whereas the statistical data was quantitative.

\subsection{Field research}

\subsubsection{Activity - analysis and results}

The project area was divided into three topological types; research centres, local activity spots, and farming areas (Fig 1). There were three field trips at the beginning of the research, each with a different focus: local activities, topology, and lighting conditions. By observing the area, two spots were determined to be central activities in the area based on size and scope.

Fig. 1. Project area

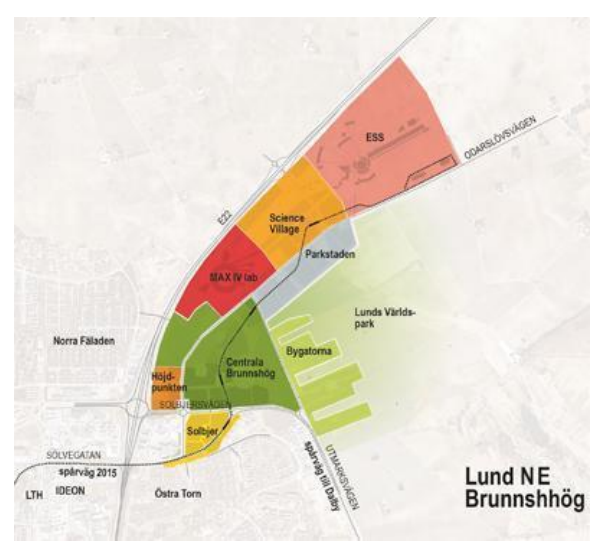

Firstly, there is a local cultivation area for growing vegetables, flowers and fruits called Odla i Lund. This area is owned by the commune and offers access for a small fee [19]. It is located in the central part of Brunnshög and has an area of about $2000 \mathrm{~m} 2$. To date, approximately 600 people have participated in the small-scale farming projects on a regular basis. The community of Odla i Lund have an online website and organize various activities and guest speakers on the topic of agriculture and horticulture.

Secondly, there is an area of fairly dense forest where willow huts are built by local children. It is a cultural and educational spot where local families, including young children, participate in educational activities, and has a more eventful character. Families bring their children to this spot to let them experience nature in a hands-on fashion.

Although the groups who used each area were different, they all revolved around spare time activities where families interact with nature. The local farming area saw mostly adults engaging in small scale agriculture. Children sometimes accompanied their adult family members, i.e., parents or grandparents, to learn about growing vegetables, plants, etc. The focus of activity was different for the willow hut area, where families with children would go exclusively for the children's sake. The activities in the willow hut area focused mainly on building in nature, and experiencing raw, uncultivated nature. In both areas, the presence of nature and the closeness to the earth functions as an essential part of the children's upbringing, and the adults' well-being. Both activities are actively organized and maintained 
by the local community of Brunnshög, and include a website. In addition, they receive municipal support, and are promoted as a model for sustainable living.

\subsubsection{Topology - analysis and results}

Whereas the fieldwork focused on the presence and activity of the groups in the area, the second visit analysed the topology of the site. During this visit, various paths were analysed, including the areas these connected. It was observed that there were more paths and connections to the residential town Norra Fäladen than connections to the large farming areas on the right side of Brunnshög. Further Ideon, a science park which is situated the closest to Solbjer, was directly linked to Brunnshög and within walking distance.

The public transport connection between Lund and Brunsshög, which currently is a bus, passes by Ideon. The municipality however has announced the development of a tram connection to strengthen the connection not only between spots in Brunnshög, but also between Brunnshög and Central Lund.

\subsection{Statistics: demographic analysis and results}

The Lund Kommune conducted and reported a pilot study called TI3 in 2012 to assess the feasibility of the city plan. It advocated creating a city where scientists and farmers could integrate and create synergy [17]. A more in-depth research into the area was conducted on the basis of statistical data of the municipality relating to other demographics. The demographic data has shown that Lund is a city centred around its university, its cooperative research centres and companies, the latter of which have developed a strong IT infrastructure. The average age in Lund is significantly lower than that of Skåne and the rest of Sweden, with $41 \%$ in the 20 to 44 age range [20]. In addition, the largest occupation of this age group was in the IT sector, predominately in mobile and computer technology fields.

\subsection{Focus group interview}

\subsubsection{Target group}

The target groups were designed after analysing the data from the field research and formal studies. Three groups were determined based on their integration into the area and their level of IT aptitude. The participants were purposefully chosen to represent the target groups. Three groups were classified: the residents of Brunsshög, young IT professionals from Lund and Malmö, and the young professionals' families. The focus group interview was conducted to firstly map the target groups' feelings, rhythms and routines, and secondly to determine what they thought was most important to their lives [21].

Due to issues of confidentiality, it was decided to conduct the focus group interview only with employees from Kraftringen, the project owner. Although their background as employees of an energy company were grounds for bias concerns, they were still considered as representative of the target group of IT professionals. A second possible bias was the lack of participants from the two local active communities, i.e., the local small-scale farming club and the willow hut building community. However, those two activity hubs have built their own social networking media such as web pages and YouTube accounts, and had been researched by the municipality before. This data substituted for the lack of representatives from these two communities.

There were 6 participants in total between the ages of 22 and 60 years old. Two participants were in their twenties, two participants were in their forties, and the final two 
participants were forty and sixty (Fig 2). There were two males and four females (Fig 3). All participants had lived in the greater Lund area (Fig 4) for one to 57 years. One participant who has lived in Malmö for a year had grown up in Lund, and thus it was assumed that all participants had deep connections with the area.

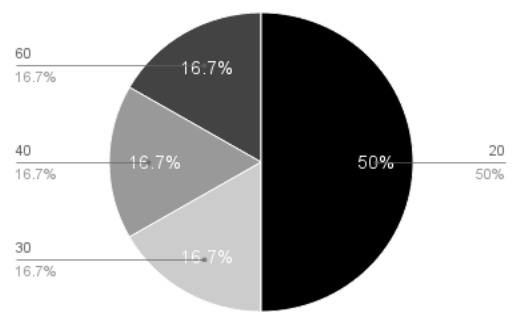

Fig. 2. Age

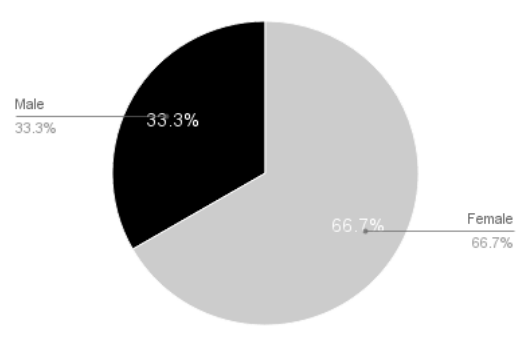

Fig. 3. Gender

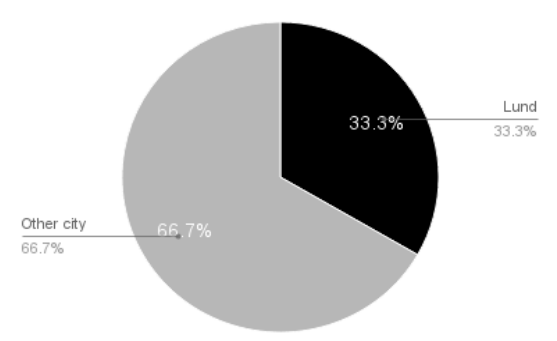

Fig. 4. Living area 


\subsubsection{Interview methodology}

Although focus group interviews are usually conducted along a structured interview methodology, the questions asked in this survey were unstructured, and produced data based on drawings and a review of the discussion. This method was carefully chosen as a tool to capture the 'ineffable sides in their life', and 'aspects that are not easily stated' [22]. To avoid bias, the aim of the survey was not revealed to the participants [23].

The interview consisted of a 15-minute drawing session and 15-20-minute discussion session, followed by questions about gender, age, place of residence, and how long they had lived in the area.

As researchers in the area of arts-based methodologies highlight, meaning-making through the arts is full of complexity. The artistic products are themselves texts to be read and interpreted by their producer and their audiences, including researchers. At the same time, the use of drawing as a research method typically involves more than just engaging participants in making drawings, followed by the researcher's analysis of these artefacts. When drawing is used as a research method, it often entails participants' drawing and talking or drawing and writing [24].

Easy and normal materials, such as colour pencils and pens, were prepared. It was key that the participants felt comfortable drawing, and were not burdened by feelings of shame for not being capable of producing nice drawings. To reassure them, it was noted that the focus was on the content of their drawing, and not its quality [24].

\subsubsection{Interview questions}

In the drawing session participants were asked to draw their ideas about three questions: how would you like to play in / with the installation spot, how do you experience electricity, and how do you experience other people. After that they were asked to explain their drawings, discuss it, and share the ideas in a comfortable atmosphere. The questions aimed to understand which conditions can lead to a sense of ownership [Q1] (Fig 5), ideas about technology [Q2] (Fig 6), and their relationship with the people and communities [Q3] (Fig $7)$.

\section{Questionnaire}

Q1: How would you like to play in / with this area? (5 min)

Please draw your idea based on the dimensions with

whom/ when/ how/ how long/ why?

Q2: How do you experience electricity? (5 min)

Q3: How do you experience other people? $(5 \mathrm{~min})$ 


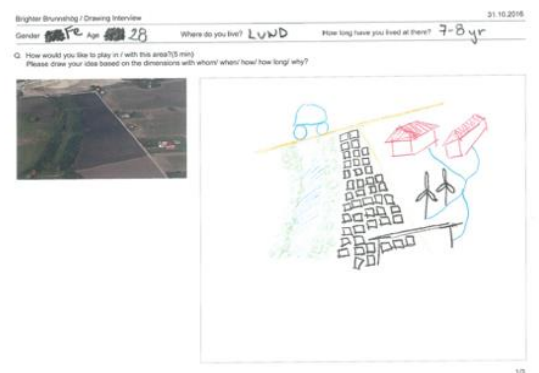

Fig. 5. How would you like to play in / with the area?

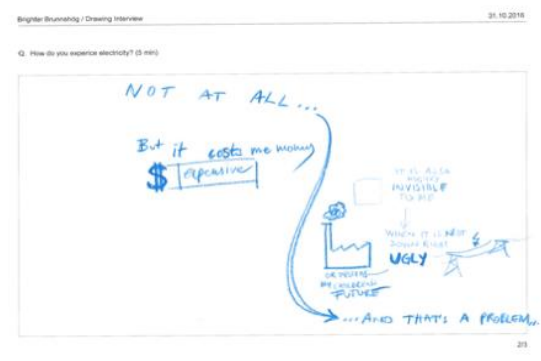

Fig. 6. How do you experience electricity?

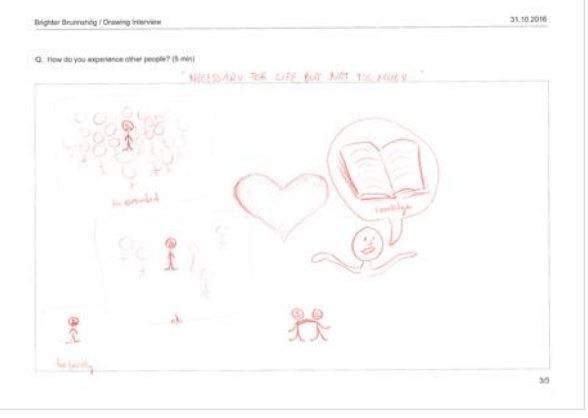

Fig. 7. How do you experience other people?

\subsubsection{Interview analysis}

The discussions after the drawing session were transcribed as the discussion took place. The collected data was analysed by the program $\mathrm{N}$-vivo to clarify the frequency of the keywords, which were subsequently grouped into themes. Most reactions related to the convenience of electricity, i.e,. a better quality of life and better connection between people. This was mentioned 17 times $(9.06 \%)$ in total during the discussion and was observed as the most frequent. The second most frequently mentioned theme related to the experience of other people, and is described as positive feelings, i.e., cosiness, warm colour lighting therapy, a number of people, soft, calm, nice view. This theme was mentioned 13 times $(9,14 \%)$. Energy 
efficiency, related to question two, included the topic of solar panels, electric cars and bicycles, and recycling, and was mentioned 10 times, (4,17\%). Outdoor activities, related to question one, included horse riding, walking, running and fishing, and was mentioned nine times $(4,20 \%)$. Finally, New technology, related to question two, included the topic of new mobile phone applications, GPS, Mega Tetris, Interactive lighting, and Tesla, and was mentioned seven times $(3.36 \%)$.

There were other trends beyond the five most frequent topics which mostly related to a concern for the environment. The participants recycled daily disposals and reduced energy consumption by being energy efficient, e.g., by using electric cars.

Furthermore, it could be said that they were regularly doing outdoor activities such as jogging, riding, swimming etc. It was suggested that those activities could be an element which could attract people to the installation on a regular basis.

The data indicated that the participants were highly interested in energy efficiency, a bias expected from this group as employees of an energy company.

\section{Artistic design development}

\subsection{Location}

The analysis was conducted to determine the main location for the lighting installation, and was based on the design criteria that the installation act as a conduit between the science part of the area with the local communal activity spots. As such, a suitable spot was found in the middle of these two areas with a long open area surrounded by trees running adjacent to the large farm (Fig 8, spot A). Accessibility for both the local and near-town people was a priority, and therefore, the proximity of the chosen spot to public transport and roads was a major determining factor in the choice.
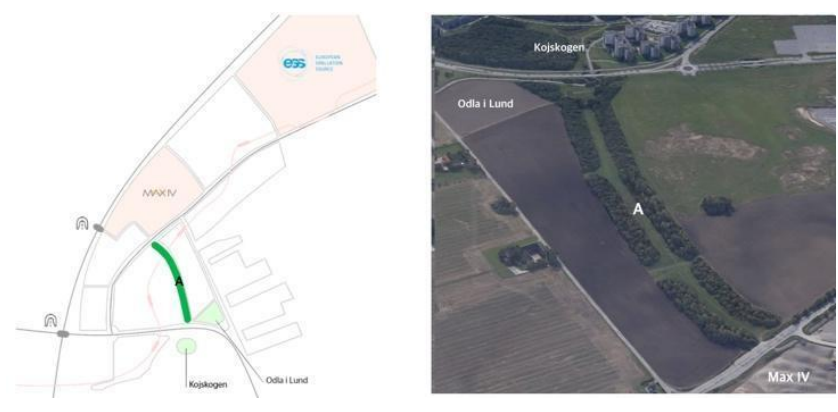

Fig. 8. Project area

The location for the lighting installation is approximately 100 meters from the MAX IV facility, and equally about 100 meters from the small-scale farming area and the adjacent willow huts forest area. There is a road running along the length of the area at about 50 meters, which connects to the road and bus route of the MAX IV facility and the science park, which in turn connects to Lund. 


\subsection{Theme}

The theme for the installation is based on the focus of the development of the area, and the activities of the local users. The urban development is heavily centred on the scientific community, which stands in stark contrast to the local farming and forest activities of the current users. It was felt that ownership over such a conceptual clash in the area could best be given by highlighting the link between technology and raw nature, and how users of nature form the vital link to scientific development. In other words, the local users could feel empowerment and ownership once they realised how the development of science, and as such the area, was dependent on them.

\subsection{Design Criteria}

On the basis of the requirements of the developers of the area, Kraftringen, and the analysis of the results of the focus group interviews, as well as the chosen theme for the installation project, three criteria were determined as guidelines for the development of the design: awareness, mutuality and adaptability (Fig 9).

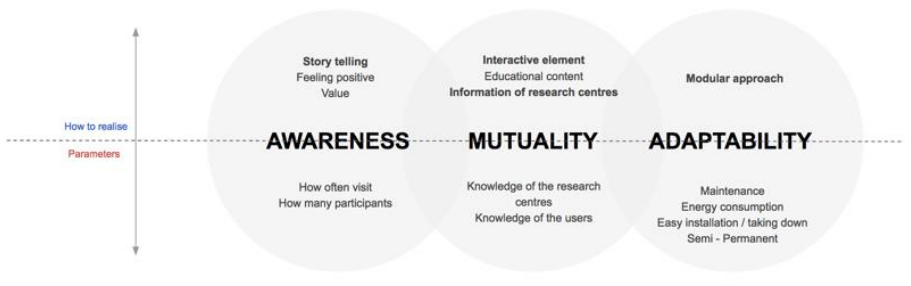

Fig. 9. Three design criteria

Firstly, 'awareness' is proposed to create a feeling of ownership in the development of the area and refers to the user's position as a medium between nature and technology. It was based on the research mostly about the local activities and question one of the focus group interview. It emphasized that the users could be seen as a medium between nature and cuttingedge technologies, i.e., the research centres.

This sense of ownership would be further strengthened by the interactive nature of the installation, the latter of which would make the users feel they are being listened to, and have a say over the development of the area. This is equally the link to the second criterion of 'mutuality', which contains information of users and research centres, so both sides can learn from each other. It is based on the understanding from demographic data that the local- and future users of the area will be tech-savvy and IT professionals, as indicated in the second question of the focus group interviews.

The interactive platform was designed to promote and allow people to easily gain access to the installation spot, and would offer a communication channel between the users and the planners, and policy makers.

Thirdly, 'adaptability' is a requirement from the developers of the area, which will allow the design to follow the stages of area development. This criterion relates to both the functional design of the installation, so it can grow and move as the urban development progresses, as well as the artistic expression of the idea of sustainability, the latter of which was revealed to be important in the focus group interview. As such, it will be easily foldable and movable, and will rely on solar power to run the lights of the installation. Adaptability was achieved by a modular design, which could be expanded upon, or reduced by the use of 
modules and units. Therefore, a Miura origami tessellation structure was proposed for the adaptable design which users could easily adjust in size and shape through physical interaction.

\section{Design proposal}

The design itself was decided to represent a portal connecting the undeveloped natural area with the developed area, and was based on the criteria of awareness, mutuality and adaptability. The model was intended to add to the variety of attractions for the chosen spot and to encourage visitors to interact with the objects.

Even though the installation will be in a virtual environment, and outside the effects of gravity, physics and weather conditions, the design still carefully considered the condition of the physical place to create a believable environment.

\subsection{Tessellation structure}

The basic module is a Miura-ori Tessellation structure (Fig 10). It is easy to stretch and fold, and can be extended by combining several modules.

Its high flexibility, i.e., foldability, was used to give a greater sense of interaction. Further, the structure is represented as stable to create a believable sense for the users who know the windy weather conditions of Brunnshög, yet with the ability to create a dramatic effect through its transforming capability.

The tessellation tunnel can thus be used by users to create a physical area which will invite people, and make them walk inside and through it. The ability to expand and compress the tunnel equally gives a greater sense of control over the object.

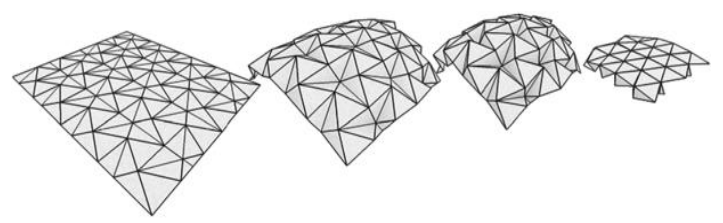

Fig. 10. An example of a Miura-ori tessellation structure.
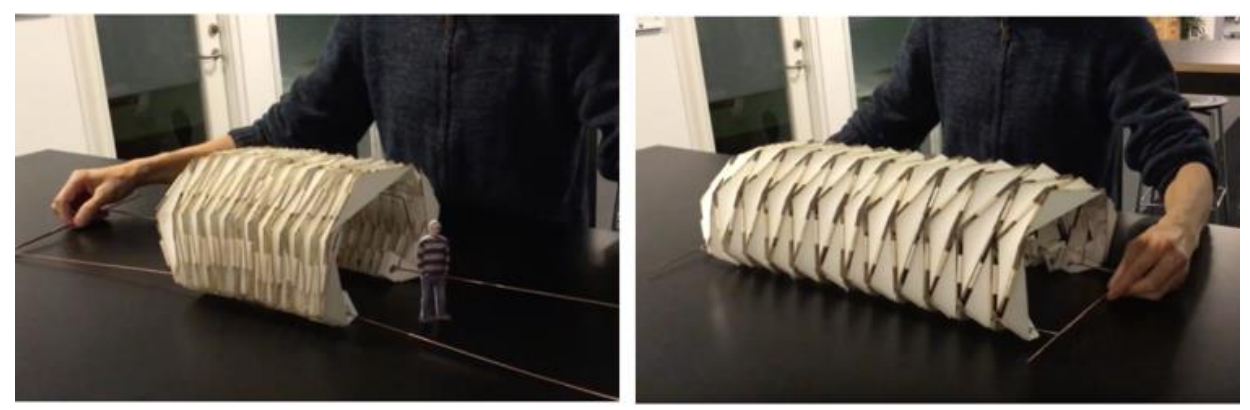

Fig. 11. Tessellation tunnel 


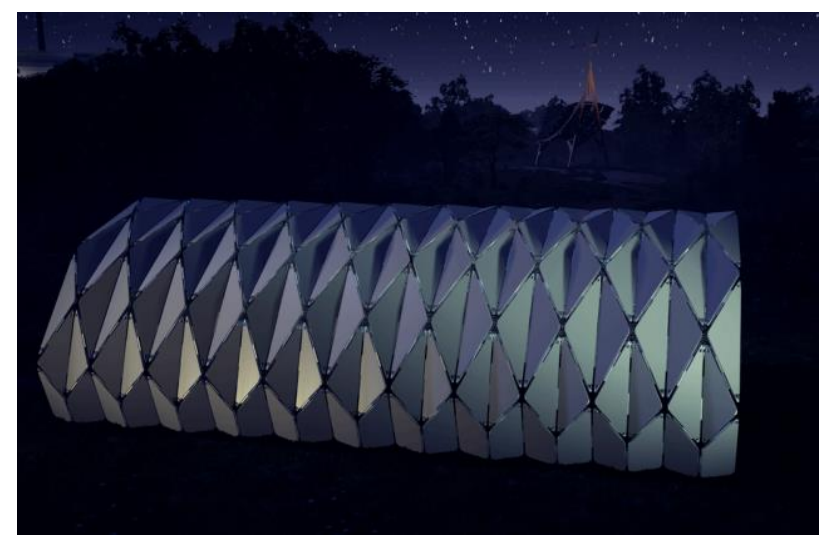

Fig. 12. Tessellation tunnel in VR

The default figure of the tunnel is short and more spherical, which when expanded, assumes a longer and semi-circular shape (Fig. 11). This creates a tunnel which faces both sides: the activity area and the research centres. At the same time the tunnel in and of itself will signify a gate of its own, connecting nature, i.e., the activity areas, with the technology areas. As such, it should stimulate a sense of awareness for the users as a medium between raw nature and cutting-edge technology. The tunnel was created using Blender and rendered in real time in Unreal Engine 4 (UE4) and transferred to its virtual environment (Fig. 12).

The structure acts as the platform for lighting delivery, and is based on three types of interactivity. Firstly, the users can manipulate the colours and intensity of the light of the tunnel by using the sensors in HTC Vive controllers. Secondly, the users' physical activity, i.e., touching the LED panels on the surfaces inside of the tunnel, changes the lighting patterns on the panels. These two main interactions can create the participants' own lighting design inside the tunnel. To change the patterns of the panel, the users are required to reach the panel. This means they have to jump or run to light up the panels in certain locations. This interaction design was proposed to encourage the users' physical movement as they are familiar with outdoor activities such as gardening, building, and horse riding. Finally, the shape of the installation is also interactive. In this interactive layer the transforming object indicates the presence of users, and it welcomes the users by opening up when it detects their presence.

By applying the same interactive concept and content to the tunnel, the users are encouraged to feel that they are participating and involved in the development project, which can stimulate the sense of ownership over the area and the development.

\subsection{Virtual environments - interaction and awareness}

The virtual environment was created in UE4 with various 2D, 3D programs such as Rhino, Blender and Photoshop. The size of the area was approximately $600 \times 600 \mathrm{~m}$ and based on the topological data from Google Earth, as well as field research, since the virtual environment primarily aimed to mimic the nature in Brunnshög in as much detail as possible (Fig. 13). The tunnel was situated in the middle of the project area as a portal and connection between the new research centres and the farming area. The users were encouraged to walk through the tunnel and interact with it by changing the LED light panels (Fig. 14). 


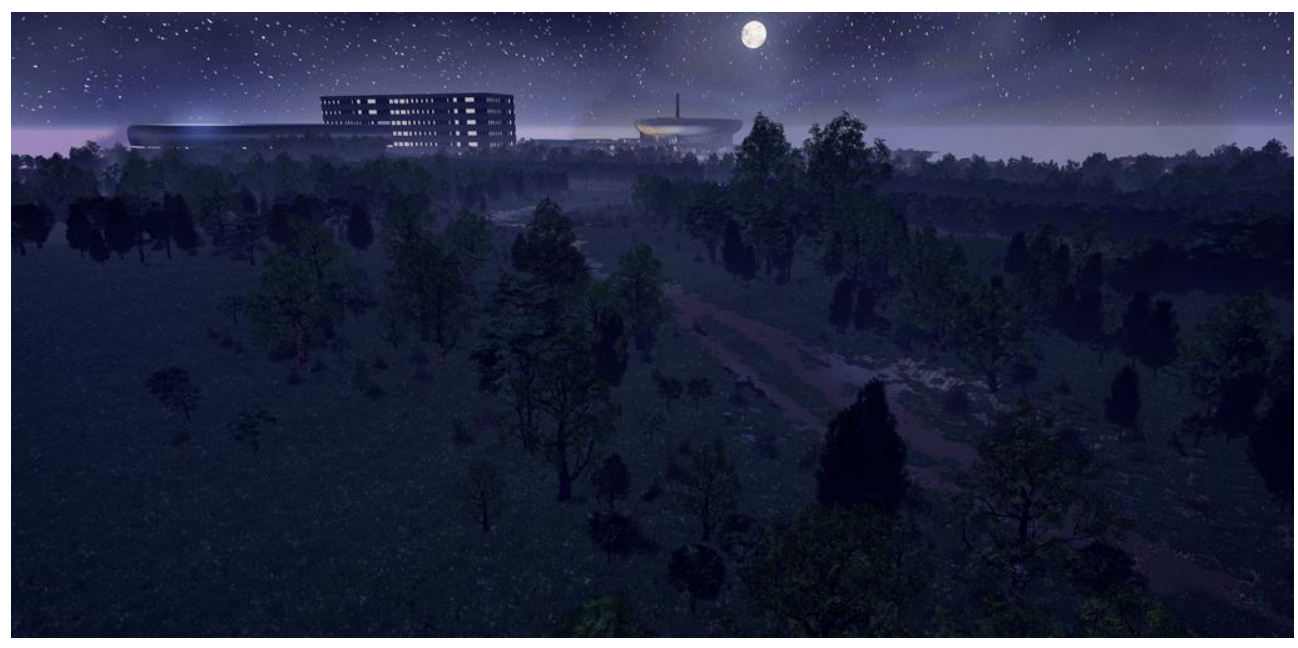

Fig. 13. Level design

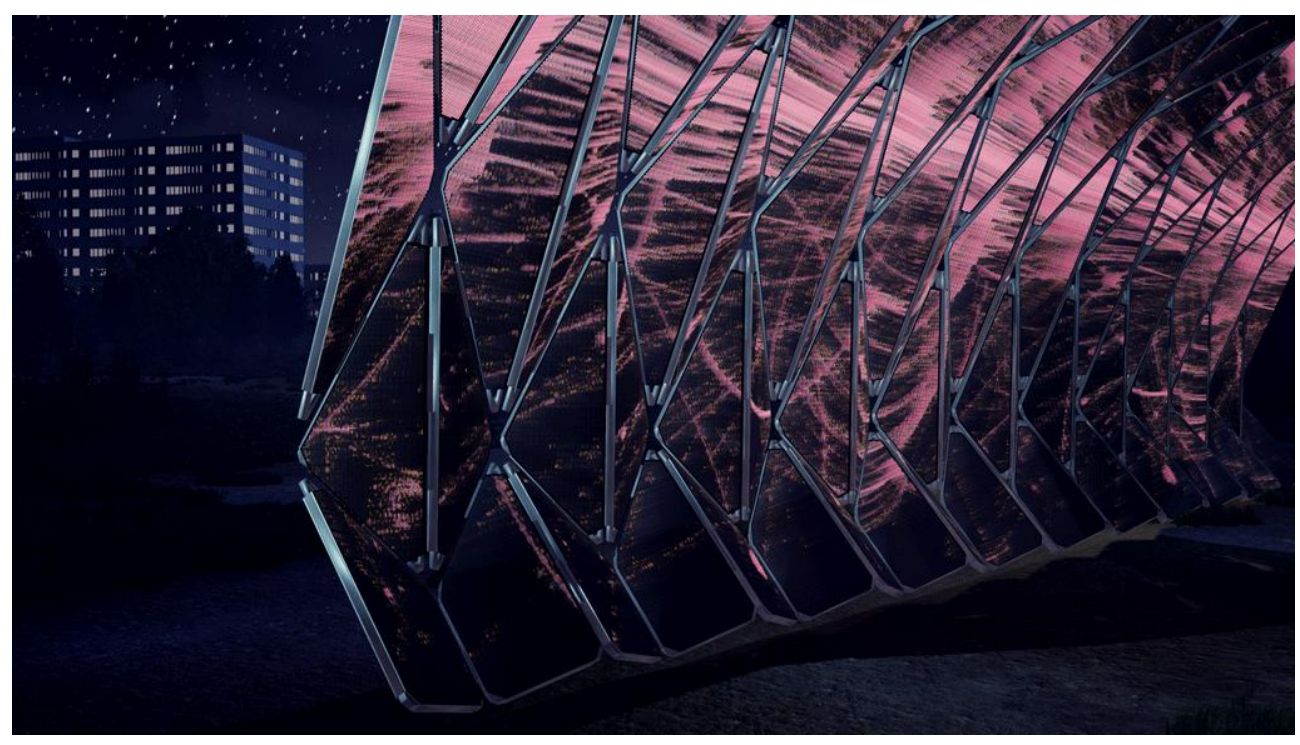

Fig. 14. Simulated LED panel

The lighting patterns in the LED panel were inspired by the neutron spallation system of the two research centres; MAX IV and ESS. They are both spallation research facilities based on different systems; MAX IV uses a circular system, and ESS (European Spallation Source) uses a linear one. The lighting patterns are designed to represent these circular and linear movements to help the users to understand the research facilities in a fun way (Fig.15). 


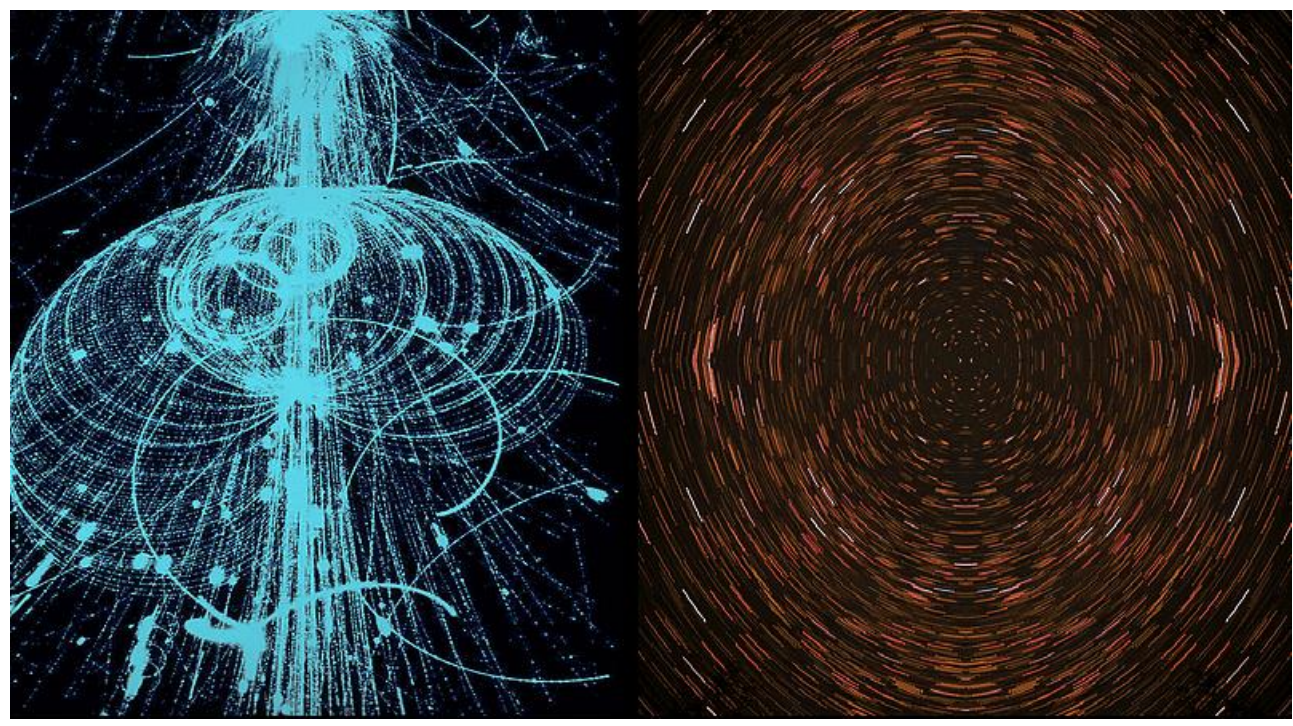

Fig. 15. Lighting patterns inspired from the spallation systems

The tunnel invites the users to pass through, and represents a journey from the undeveloped natural area to the developed area. Along the direction of the tunnel, users interact with the tunnel, which primes them to understand the development of the new area. When the users exit the tunnel, they can visit several buildings that have already been built as part of the development project, and get information about these new research centres. Several landmarks in Brunnshög and Lund were equally created to inform the users with topological information of the area. By encouraging the users to navigate the areas to collect the information, the users can understand more about the past, present, and future of Brunnshög. With this better knowledge of the area, the users are encouraged to feel that they really know the area, the latter of which is a fundamental condition to create a sense of ownership over the area.

\section{Test}

The proposed design has shown that an art-based lighting design is feasible to create art, and combine it with design based on research, and that in line with any research, it can be tested with respects to falsifiability to see if, in this case, the installation provides a sense of ownership over the urban development project [25].

The test for the hypothesis was conducted by qualitatively assessing parameters connected to notions of a 'sense of ownership'. These parameters were studied before and after the participants experienced the installation and the virtual environment.

\subsection{Pilot test}

An early pilot study on 21 subjects, ages 25 to 59 , was conducted to assess the feasibility and the design of the tests. The test subjects who participated in the pilot study were employees from Kraftringen, the project owner.

Overall, the test clearly showed that the experience of the lighting art installation in virtual reality increased the awareness of the area and a positive attitude toward the development of 
the area. The test questions were formulated to firstly ask the about users' perception, knowledge, and the connections to the area before and after their experience of VR. Secondly, the users were asked if they felt a sense of control and participation during their experience in the tunnel. (Fig. 16). In the first part of the questions, the users answered that they had more positive feelings of Brunnshög, and more knowledge of the development of the area. They also felt the development connected to sustainability, innovation and technology. Nevertheless, their feeling of control and participation in the interaction of the tunnel was not strong, and it was considered that this was primarily due to the complexity of interaction with controllers. Furthermore, this pilot study equally indicated that it was difficult to detect signs and paths while the users navigated the area. (Table.1). Therefore, after careful consideration and research about perception of visual recognition and optimized UX design, the level design was optimized by applying emissive materials on signs and removing some foliage on the path in the virtual Brunnshög. Furthermore, the lighting interaction was simplified by using only one controller. (Fig.17).

The results were considered biased since the employees of the project owner had a greater chance of being exposed to information about the project.

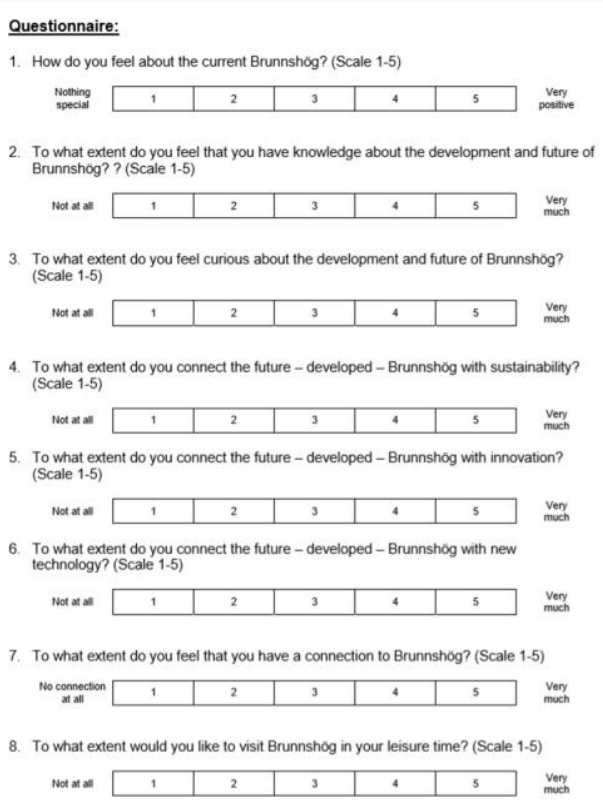

Fig. 16. Questionnaire for pilot test
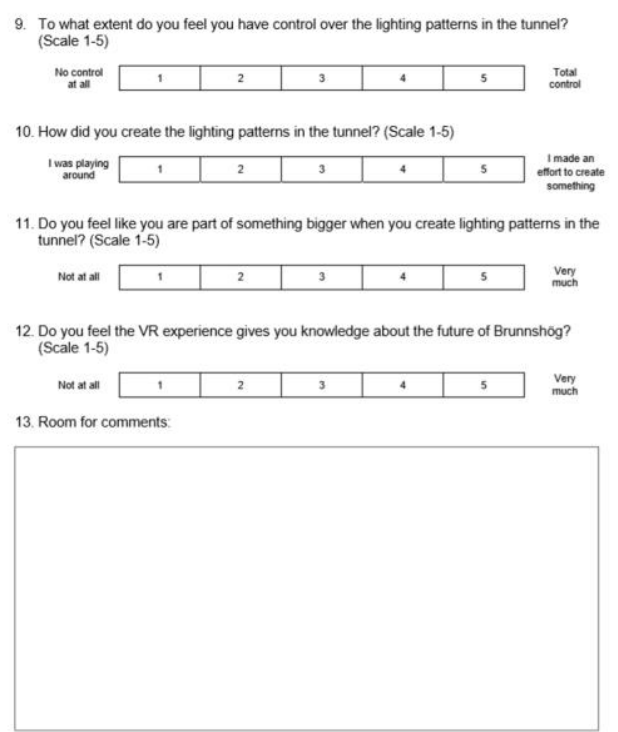
Table 1. Data from the pilot test

\begin{tabular}{|c|c|c|c|c|c|c|c|c|c|c|c|c|c|c|c|c|c|c|c|c|c|c|c|c|c|}
\hline & \multicolumn{8}{|c|}{ Question nbr (before): } & \multicolumn{12}{|c|}{ Question nbr (after): } & \multirow[b]{2}{*}{$\begin{array}{l}\text { Gender } \\
\text { (Male/ } \\
\text { Female) }\end{array}$} & \multirow[b]{2}{*}{ Age } & \multirow[b]{2}{*}{$\begin{array}{l}\text { Visual } \\
\text { imparime } \\
\text { nt that } \\
\text { affects } \\
\text { the VR- } \\
\text { experienc } \\
\text { e? }\end{array}$} & \multirow[b]{2}{*}{$\begin{array}{l}\text { Resident } \\
\text { in Lund? }\end{array}$} & \multirow[b]{2}{*}{$\begin{array}{l}\text { Ever } \\
\text { Been to } \\
\text { Brunnsh } \\
\text { ög? }\end{array}$} \\
\hline Participan & Q1 & Q2 & Q3 & Q4 & Q5 & Q6 & Q7 & Q8 & Q1 & Q2 & Q3 & Q4 & Q5 & Q6 & Q7 & Q8 & Q9 & Q10 & Q11 & Q12 & & & & & \\
\hline 1 & 1 & 3 & 5 & 4 & 4 & 4 & 2 & 4 & 1 & 3 & 5 & 4 & 4 & 4 & 3 & 5 & 3 & 2 & 2 & 2 & $\mathrm{M}$ & 32 & $\mathrm{~N}$ & $\mathrm{~N}$ & Rarely \\
\hline 2 & 3 & 2 & 4 & 4 & 4 & 3 & 1 & 2 & 2 & 3 & 4 & 4 & 4 & 4 & 2 & 2 & 3 & 3 & 3 & 3 & $M$ & 43 & $\mathrm{~N}$ & $\mathrm{~N}$ & Yearly \\
\hline 3 & 3 & 2 & 4 & 4 & 4 & 4 & 1 & 2 & 3 & 4 & 4 & 5 & 5 & 5 & 3 & 4. & 4 & 2 & 3 & 4 & $\mathrm{~F}$ & 27 & $\mathrm{~N}$ & Y & Rarely \\
\hline 4 & 5 & 3 & 5 & 4 & 5 & 5 & 3 & 5 & 5 & 4 & 5 & 4 & 5 & 5 & 4 & 5 & $x$ & $x$ & $x$ & $x$ & $M$ & 48 & $\mathrm{~N}$ & $\mathrm{~N}$ & Rarely \\
\hline 5 & 3 & 3 & 5 & 5 & 5 & 5 & 4 & 5 & 5 & 3 & 6 & 6 & 5 & 5 & 4 & 5 & 3 & 5 & 5 & 5 & $M$ & 56 & C & $\mathrm{N}$ & No \\
\hline 6 & 5 & 5 & 5 & 5 & 4 & 4 & 5 & 3 & 5 & 5 & 5 & 5 & 4 & 4 & 5 & 4 & 4 & 3 & 4 & 5 & M & 59 & $\mathrm{~N}$ & $\mathrm{~N}$ & Monthly \\
\hline 7 & 4 & 4 & 4 & 3 & 4 & 5 & 4 & 3 & 4 & 4 & 4 & 4 & 5 & 5 & 4 & 4 & 4 & 2 & 3 & 2 & M & 38 & C & Y & Yearly \\
\hline 8 & 3 & 4 & 3 & 3 & 3 & 4 & 2 & 2 & 3 & 4 & 3 & 3 & 3 & 3 & 2 & 2 & 2 & 1 & 1 & 1 & M & 54 & C & Y & Monthly \\
\hline 9 & 1 & 2 & 5 & 4 & 5 & 5 & 1 & 4 & 4 & 3 & 5 & 4 & 5 & 5 & 3 & 5 & 4 & 1 & 4 & 5 & $\mathrm{~F}$ & 38 & $\mathrm{~N}$ & Y & Yearly \\
\hline 10 & 1 & 3 & 3 & 2 & 4 & 4 & 1 & 3 & 2 & 2 & 3 & 3 & 3 & 3 & 1 & 3 & 2 & 1 & 1 & 2 & M & 28 & $\mathrm{~N}$ & $\mathrm{~N}$ & Rarely \\
\hline 11 & 4 & 2 & 3 & 3 & 3 & 3 & 2 & 2 & 4 & 3 & 4 & 4 & 4 & 4 & 3 & 3 & 4 & 2 & 3 & 4 & $\mathrm{M}$ & 37 & $\mathrm{~N}$ & $\mathrm{~N}$ & No \\
\hline 12 & 2 & 4 & 5 & 4 & 3 & 3 & 3 & 5 & 4 & 4 & 5 & 4 & 4 & 3 & 3 & 5 & 2 & 2 & 2 & 3 & M & 51 & C & $\mathrm{N}$ & Yearly \\
\hline 13 & 3 & 3 & 4 & 4 & 4 & 4 & 2 & 3 & 5 & 4 & 5 & 5 & 5 & 5 & 5 & 4 & 5 & 1 & 3 & 4 & M & 28 & $\mathrm{~N}$ & Y & Rarely \\
\hline 14 & 5 & 3 & 5 & 5 & 4 & 4 & 4 & 3 & 5 & 4 & 5 & 5 & 4 & 4 & 4 & 4 & 4 & 1 & 4 & 4 & $\mathrm{~F}$ & 54 & P & Y & Yearly \\
\hline 15 & 1 & 2 & 4 & 5 & 5 & 5 & 3 & 1 & 2 & 2 & 5 & 5 & 5 & 5 & 4 & 4 & 4 & 2 & 3 & 4 & $\mathrm{~F}$ & 50 & $B, P$ & N & Yearly \\
\hline 16 & 1 & 4 & 5 & 5 & 5 & 4 & 2 & 1 & 1 & 4 & 5 & 5 & 5 & 5 & 3 & 1 & 4 & 1 & 3 & 4 & M & 26 & $\mathrm{~N}$ & Y & Yearly \\
\hline 17 & 4 & 4 & 4 & 5 & 5 & 4 & 3 & 3 & 3 & 4 & 5 & 4 & 5 & 5 & 4 & 4 & 3 & 1 & 3 & 3 & $\mathrm{~F}$ & 25 & $\mathrm{~N}$ & N & Yearly \\
\hline 18 & 5 & 5 & 5 & 5 & 5 & 5 & 5 & 4 & 5 & 5 & 5 & 5 & 5 & 5 & 5 & 5 & 3 & 1 & 3 & 3 & M & 28 & $\mathrm{~N}$ & Y & Yearly \\
\hline \multirow[t]{2}{*}{19} & 4 & 5 & 4 & 4 & 5 & 5 & 4 & 2 & 4 & 5 & 4 & 4 & 5 & 5 & 4 & 2 & 2 & 1 & 2 & 1 & $\mathrm{M}$ & 52 & $\mathrm{~N}$ & Y & Monthly \\
\hline & 58 & 63 & 82 & 78 & 81 & 80 & 52 & 57 & 67 & 70 & 87 & 83 & 85 & 84 & 66 & 71 & 60 & 32 & 52 & 59 & & & & & \\
\hline Average & 3.05 & 3.32 & 4.32 & 4.11 & 4.26 & 4.21 & 2.74 & 3.00 & 3.53 & 3.68 & 4.58 & 4.37 & 4.47 & 4.42 & 3.47 & 3.74 & 3.33 & 1.78 & 2.89 & 3.28 & & & & & \\
\hline Percent & $16 \%$ & $11 \%$ & $6 \%$ & $6 \%$ & $5 \%$ & $5 \%$ & $27 \%$ & $25 \%$ & & & & & & & & & & & & & & & & & \\
\hline \multirow{2}{*}{ Percentag } & $9 \%$ & $7 \%$ & $5 \%$ & $5 \%$ & $4 \%$ & $4 \%$ & $15 \%$ & $15 \%$ & & & & & & & & & & & & & & & & & \\
\hline & & & & & & & & & & & & & & & & & & & & & & & $\begin{array}{l}\text { C-Corrected } \\
\text { P-presbyopia } \\
\text { B-Color blind }\end{array}$ & & \\
\hline
\end{tabular}

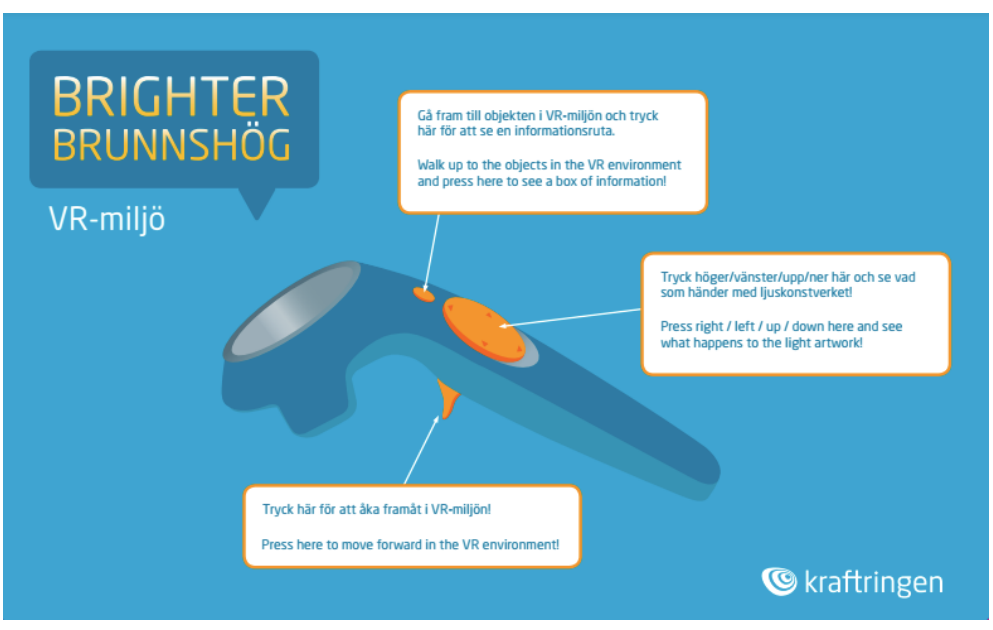

Fig. 17. Controller 


\subsection{Test}

The test was conducted on 16th of Sep in IKDC, Lund, Sweden, where the project was presented during Kulturenatten 2017 in Lund, Sweden. As the city hosts many international residents belonging to the university and global companies, the tests were prepared in Swedish and English.

\subsubsection{Participants}

In total, 22 subjects volunteered to participate. Before they tried the VR simulation, each was asked to complete a questionnaire regarding gender, vision, age, living of area and if they had knowledge of Brunnshög. After completing the form, each participant was escorted into the VR room. The participants were tested separately, which took around 5 minutes each, and afterwards they were asked again to fill in the questionnaire. The two questionnaires were the same in order to assess whether, and in which way, the VR experience could change the participant's opinions.

The ages of the participants were between 12 and 50 years, with 6 participants who did not fill in their age. The mean was 35.6 years, the median was 37 years, and the standard deviation was 10.85 . Of the 22 participants, 7 were women $(31.8 \%), 9$ were men $(40.1 \%)$, and 6 did not mention their gender (27\%). 11 of the participants $(50 \%, 4$ males, 4 females, 3 unknown gender) reported normal vision. 8 participants $(36.3 \%, 4$ males, 3 females, 1 unknown gender) stated that they required, and were wearing glasses. Two participants with unknown gender did not report the condition of their vision, and only one participant $(4.5 \%$, male) was colour blind. 16 participants $(72.7 \%, 10$ males, 6 females) reported they were residents in Lund, and two participants ( $9 \%$, unknown gender) did not state where they lived. Four participants $(18.1 \%, 1$ male, 2 females, 1 unknown gender) answered they visited Brunnshög less than once in a year, four participants $(18.1 \%, 1$ male, 1 female, 2 unknown gender) stated they visited Brunnshög annually, three participants (13.6\%, 2 males, 1 female) stated that they visited the area on a monthly basis, three participants $(13.6 \%$. 1 male, 2 unknown gender) stated that they dropped by the area on a daily basis, five participants $(22.7 \%, 2$ males, 3 females) said they had never visited Brunnshög, and two participants with unknown gender did not state whether or not they visited Brunnshög (Table 2).

\subsubsection{Test methodology}

The questionnaire was conducted in front of the VR room, which was $4 \times 4 \mathrm{~m} 2$ and which had its windows and walls covered with a dark green fabric. The questionnaire was optimized based on the results of the pilot test. The questionnaire used a 5-step Likert scale, and had an open comment box. The questions were divided into three sections. The first section asked about the participants' demographic information such as age, gender and living area. In the second section, the participants were asked about their attitude and knowledge of the development of the area. These two sections were answered by the participants before and after their experience in the VR installation. An additional section was added in the questionnaire after the VR experience, which related to the topic of control and experience. Within this, the users were asked if they felt sense of control over the lighting patterns, and if the interaction gave them a sense of being involved in something greater. (Table 2). Two instructors guided the test outside of the VR room. Further, participants were instructed in the use of the controller while they waited for their turn. Due to time constraints, and based on the pilot test, the time for the experience for each person was set to $5 \mathrm{~min}$. 


\subsection{Findings and analysis}

\subsubsection{Attitude and awareness}

The VR experience influenced the users' attitude and awareness about the area. The participants had generally neutral feelings toward the Brunnshög area. After the experience there was a $13 \%$ increase in positive attitude.

In the category of awareness, there was an increase in the following sub-categories: knowledge and curiosity about the project, knowledge about the connection of the project to sustainability, and innovation and new technology.

Knowledge and curiosity about the development of Brunnshög increased by $15 \%$ and $16 \%$ respectively after experiencing the VR installation. In the sub-categories relating to knowledge about the project and sustainability, innovation and new technology, there was equally an increase in awareness. Prior to the VR experience, users had already connected the future development of Brunnshög to sustainability, yet this increased by 17 percent after the VR experience. This was equally the case for the project's connection to the idea of innovation and new technology. Although there were already a few users who had some awareness that the development project had something to do with innovation and new technology, after the VR-experience, this increased by $16 \%$ and $11 \%$ percent respectively. In addition, the users' sense of connection to the area was initially low, yet increased by $15 \%$ after the VR experience. Finally, although few indicated they would visit the area in their leisure time, the desire to visit was increased by $13 \%$ after the VR experience.

\subsubsection{Feeling of control and involvedness in the development}

As opposed to the categories of attitude and awareness of the development of the area, assessing the sense of control and importance for the development of the area was more complicated with a greater variety of responses. Regarding the sense of control over the lighting patterns, 13 participants (59\%, 7 males, 5 females, one unknown gender) reported that they had a great sense of control (Likert scale 4), but one participant (4.5\%, female) reported she did not have control. Overall however, the participants stated that they felt they had control over the lighting patterns ( $73 \%$ positive). They felt that they played with the light rather than creating something special (48\% positive). Four participants $(18.1 \%, 2$ males, 2 females) reported they felt they created something special, whereas seven participants $(31.8 \%$ 4 males, 2 females, 1 unknown gender) said they just played with the light. The participant's sense of being part of something bigger were also very contradictory. While nine participants (41\%, 3 males, 4 females, 2 unknown gender) reported they felt they were part of something bigger (Likert scale 4$)$, ten participants (45\%, 5 males, 1 female, 4 unknown gender) marked lower than a 2 on the Likert scale ( $57 \%$ positive). 
Table 2. Data from the test

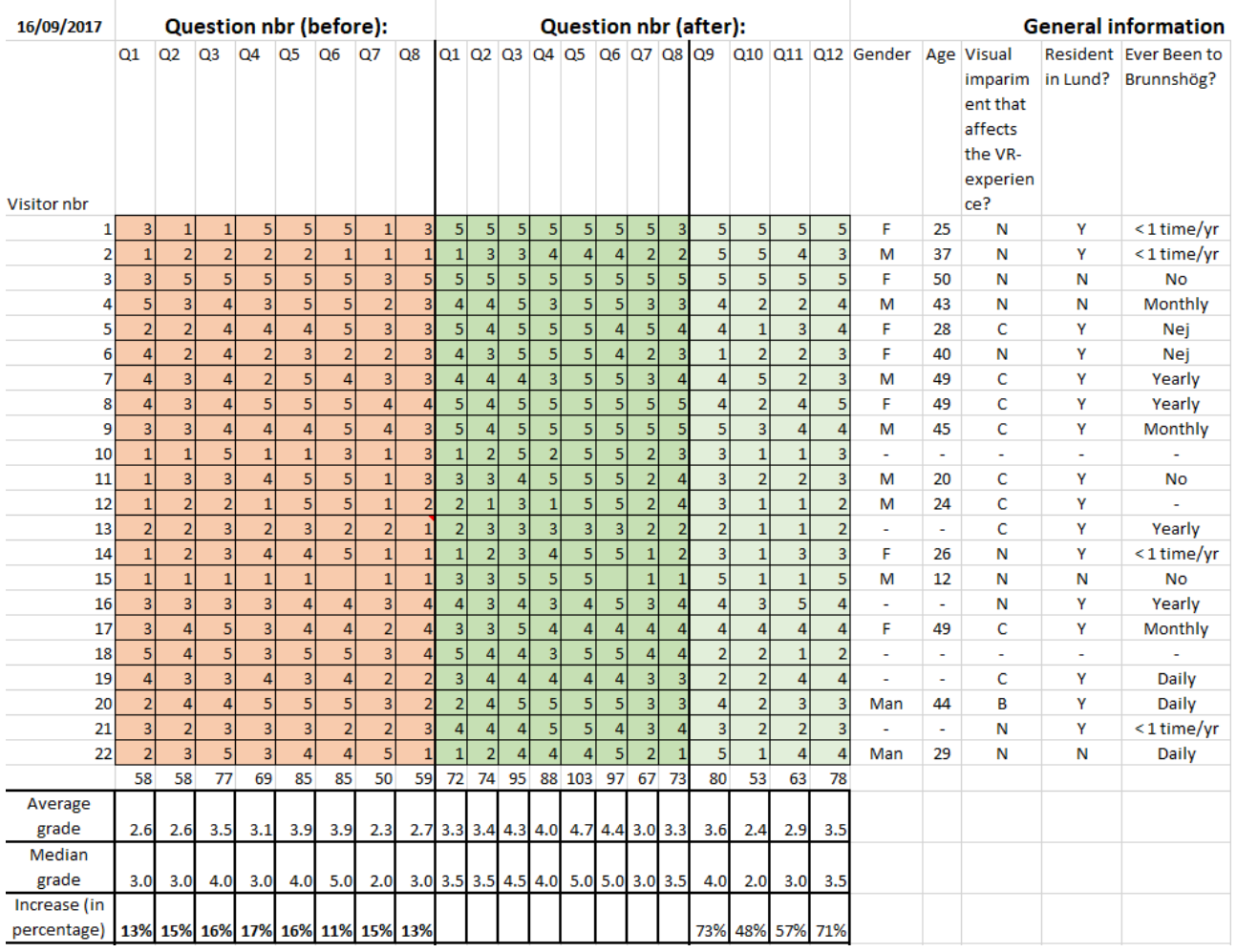

\section{Discussion and conclusion}

This article explored the potential of using interactive lighting art installations in virtual environments to stimulate a sense of ownership over the urban development of Brunnshög, Sweden. As psychological ownership is a complex phenomenon which can be achieved under certain conditions, this research tried to weave various relevant elements from the wider scope of art, design, anthropology, psychology and urban development studies in the design development of this project. Thus, the design aimed to create an installation which fostered the users' knowledge, sense of control, and feeling of involvement over the area which was under development.

It was highlighted during the urban planning for Brunnshog that the current residents of the area had not been integrated in the planning, even though they were a central element of the local identity and culture. As such, the designers set out to integrate the local residents in a design in which the residents became the conduit between the past, present and future of the area, based on three design criteria: awareness, mutuality and adaptability. Awareness was achieved through the virtual visualization of Brunnshög in which information about the future plans were virtually displayed in a 3D immersive environment. Mutuality criterion was carried out by encouraging users to interact with the tunnel installation and allowing them to explore "Virtual Brunnshög". Finally, by requiring an adaptable approach to design, VR technology allowed the exhibit to be demonstrated anywhere with a minimum amount of equipment and time: a computer and HMD. It equally made it easily accessible for people, including those with disabilities. 
Regarding the design of the actual lighting installation, the conducted research on the area and its residents, resulted in the proposal of the tessellation tunnel that was meant to symbolize a portal connecting the current and future Brunnshög. Participants were encouraged to interact with light inside the virtual tunnel and create their own lighting design while they walked through and, in the direction of, where the future Brunnshög was displayed. The interaction was designed to allow for a simple control over the lights and patterns inside the installation.

This project was realized in a virtual environment with UE4 and various 2D, 3D programs, and experienced through HTC Vive. It was cost effective compared to constructing and maintaining a real installation in terms of budget and safety. The test results indicated an increase in positive attitude, as well as knowledge of the area and its development after experience of the VR-installation. With respects to the sense of control and sense of involvement, these were shown to increase partially, yet remained inconclusive due to the variation in responses on the whole.

Based on the overall test results of the effects of the lighting art installation in its virtual environment, this paper argues for the use of VR based lighting art installations as a costeffective platform in multi-disciplinary urban design projects to affect a positive involvement of inhabitants. Although the results remain inconclusive with respects to sense of ownership, there were strong indications that its prerequisites, i.e., knowledge, sense of control and involvedness were positively affected by the experience of the installation, with almost half of the participants stating that they felt they were part of something bigger.

The present study builds upon a previous study [15] by exploring the usage of Virtual Environments in the process of designing and experiencing lighting installations. It was previously explored how VR's ability to create spatial experiences enabled designers to conceptually experiment with their designs digitally [15]. This paper attempted to understand how content and interaction could increase and strengthen the usage of VR technology in lighting design. In particular, it sought to understand how the experience of virtual lighting installations and virtual spaces could achieve familiarity and a sense of ownership over urban development projects.

\section{Acknowledgments}

This work was held in the context of the project Lighting Metropolis, a collaboration between Kraftringen, Aalborg University Copenhagen and Lund Municipality. The authors would like to especially thank Sara Kralmark, Eva Erdös from Kraftringen, and Andrei-Ducu Predescu from Aalborg University for their great feedback and support.

\section{References}

1. L. Scannell, R. Gifford, Defining Place Attachment: A tripartite organizing framework, Journal of Environmental Psychology, 30(1), 1-10 (2010)

2. D. Kahneman, A. Tversky, Choices, Values, and Frames, APA, 39(4), 341-350 (1984)

3. S. Marks, J. Davis, Does User Participation Lead to Sense of Ownership for Rural Water Systems? Evidence from Kenya. World Development, 40(8), 1569-1576 (2012)

4. J. Reb, T. Connolly, Possession, Feelings of Ownership, and the Endowment Effect, Judgement and Decision Making, 2(2), 107-114 (2007)

5. M. Strahilevitz, G. Loewenstein, The Effect of Ownership History on the Valuation of Objects, Journal of Consumer Research, 25(3), 276-289, (1998) 
6. W. Baxter, M. Aurisicchio and P. Childs, A psychological ownership approach to designing object attachment, Journal of Engineering Design, 26 (4-6), 140-156 (2015)

7. L. Van Dyne, J. Pierce, Psychological Ownership and Feelings of Possession: three field studies predicting employee attitudes and organizational citizenship behavior, Journal of Organizational Behavior, 25(4), 439-459 (2004)

8. D. Vandewalle, L. Van Dyne, T. Kostova, Psychological Ownership: An Empirical Examination of its Consequences. Group \& Organization Management, 20(2), 210-226 (1995)

9. G. Cupchik, J. Laszlo, Emerging Visions of the Aesthetic Process, Cambridge: Cambridge University Press.1st ed., 53(4): 64-83. (1992)

10. S, Schemel, F. Dohna, L. Schwendinger, Cities Alive: Rethinking the Shades of Night, (Foresight, Arup, 2015)

11. M. Arefi, Non-place and placelessness as narratives of loss: Rethinking the notion of place, Journal of Urban Design, vol. 4, no. 2, 179-193 (1999)

12. E. J. Lee, S.H.Ryu, A study on the development of the site-specific public art in public design, KSBDA, 14(20), 299 (2013)

13. E. Sanders, P. Stappers, Co-creation and the New Landscapes of Design, Codesign, 4(1), 5-18 (2008)

14. J. Sharp, V. Pollock, R. Paddison, Just Art for a Just City: Public art and social inclusion in urban regeneration, Urban Studies, 42(5), 1001-1023 (2005)

15. B. Kim, E. Xylakis, G. Triantafyllidis, Designing a Lighting Installation through Virtual Reality Technology- the Brighter Brunnshög case study, ArtsIT 2017, (to be published)

16. N. Tannenbaum, J. Spradley, Participant Observation, Anthropological Quarterly, 53(4), 260 (1980)

17. Lunds Kommun, TI3 (Holmbergs, 2012)

18. J.W. Creswell, V. L. Clark, Designing and Conducting Mixed Methods Research (Sage, 2011)

19. Stadsodling - Odla i Lund - Uppleva \& göra - Lund, Lund.se. Retrieved 27 December, from https://www.lund.se/odlailund (2016)

20. Lunds Kommun, Municipal facts (Scb.se, 2016)

21. J. Billson, Conducting focus group research across culture, $\mathrm{WeD}, 27$ (2006)

22. S. Weber, Visual Image in Research, in J. G. Knowles \& A. L. Cole (Eds.), Handbook of the arts in qualitative research: Perspectives, methodologies, examples, and issues, (Sage, Los Angeles, 2008)

23. D. Morgan, Focus groups as qualitative research, Thousand Oaks, Calif, 1, 32-46 (1997)

24. L. Theron, C. Mitchell, A. Smith, J. Stuart, Picturing research (Sense, Rotterdam, 2011)

25. M. Kendall, K. Popper, The Logic of Scientific Discovery, Biometrika, 46(12), 265, (1959) 